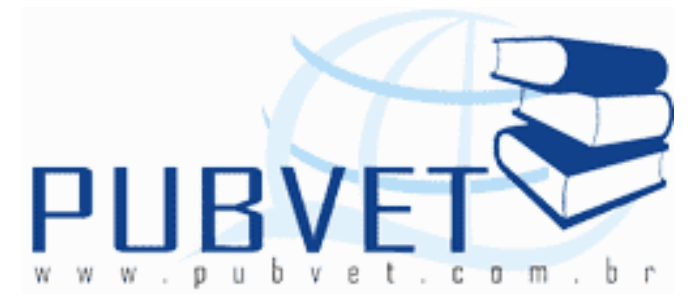

PUBVET, Publicações em Medicina Veterinária e Zootecnia.

\title{
Uso de fontes lipídicas em dietas de ruminantes de aptidão leiteira
}

\section{Isaac Ferreira de Lima Junior ${ }^{1}$, Anderson Neves Figueiredo ${ }^{1}$, Diogo Augusto Ferreira ${ }^{1}$, Marcos Elias Duarte ${ }^{1}$, Tania Marta Carvalho dos Santos ${ }^{2}$, Geovanny Soares Pauferro Barroso ${ }^{3}$, Yamina Coentro Montaldo ${ }^{4}$}

${ }^{1}$ Mestrando do Programa de Pós-Graduação em Zootecnia - UFAL/Universidade Federal de Alagoas BR 104 NORTE 85 - MATA DO ROLO - 57100 - 000 - Rio Largo, AL - Brasil.

${ }^{2}$ Profa. Dra. - UFAL

${ }^{3}$ Acadêmico de Agronomia - UFAL

${ }^{4}$ Doutoranda do Renorbio - UFAL

\section{Resumo}

A produção de leite é um processo metabólico altamente dependente de energia. No início da lactação, ocorrem simultaneamente redução da capacidade de ingestão de matéria seca (MS) e elevação das exigências energéticas em razão da maior produção, desta forma animais de alta produção encontram-se em balanço energético negativo (BEL). O uso de fontes lipídicas em dietas para ruminantes em lactação pode ser visto como uma alternativa interessante para minimizar esse efeito, no entanto algumas implicações devem ser consideradas, como alterações nos padrões da fermentação ruminal e da digestibilidade da matéria seca (MS) como também alteração de parâmetros sanguíneos. Contudo a inclusão de fontes lipídicas 
pode ser utilizada para aumentar os níveis de gordura no leite e melhorar o perfil de ácidos graxos insaturados, criando a possibilidade de remuneração por qualidade de sólidos. A presente revisão tem o objetivo de discutir a literatura sobre o uso de lipídios em dietas para ruminantes leiteiros sob os parâmetros do consumo e digestibilidade, fermentação ruminal, metabólitos sanguíneos e produção e composição do leite.

Palavras-chave: ácidos graxos insaturados, lactação, nutrição.

\title{
Use of lipid sources in diets for dairy ruminants release
}

\begin{abstract}
Milk yield a metabolic process is highly energy-dependent. In early lactation, occur simultaneously reducing the capacity of intake of dry matter (DM) and increase in energy requirements due to higher production, thus high production animals are in negative energy balance (BEL). The use of lipid sources in diets for lactating ruminants can be seen as an interesting alternative to minimize this effect, however some implications should be considered, such as changes in patterns of rumen fermentation and digestibility of dry matter (DM) as well as changes blood parameters. However the inclusion of lipid sources can be used to increase fat levels in milk and raise the profile of unsaturated fatty acids, creating the possibility of compensation for solid quality. This review aims to discuss the literature on the use of lipids in diets for dairy ruminants under the parameters of the intake and digestibility, ruminal fermentation, blood metabolites and milk production and composition.
\end{abstract}

Keywords: unsaturated fatty acids, lactation, nutrition.

\section{INTRODUÇÃO}

A produção de leite é um processo metabólico altamente dependente de energia. No início da lactação, ocorrem simultaneamente redução da 
capacidade de ingestão de MS e elevação das exigências energéticas, em razão da maior produção. Assim, os animais, por meio da homeorresia (BAUMAN, 2000), mobilizam suas reservas corporais para atender esta condição fisiológica. Modificações nas características da dieta podem ser responsáveis por várias alterações no metabolismo ruminal, nos processos digestivos e, conseqüentemente, dos nutrientes que chegam ao duodeno. Apesar dessas alterações, a inclusão de fontes de óleo na dieta de ruminantes é uma alternativa para o atendimento às exigências de energia de animais de alta produção leiteira.

Os lipídios são considerados fontes energéticas com alta concentração de energia prontamente disponível, pois são constituídos de grande proporção de ácidos graxos, os quais possuem 2,25 vezes mais energia que os carboidratos. No entanto, alguns tipos de gorduras suplementares podem alterar a composição e as características físico-químicas do leite, como no caso daquelas com elevado teor de ácidos graxos insaturados. A composição do leite, principalmente o teor protéico, pode ser reduzida, quando se fornecem lipídios em dietas de vacas em lactação. A redução da proteína do leite tem sido explicada pela redução da síntese microbiana, uma vez que lipídios não são fontes de energia para o crescimento microbiano (SNIFFEN et al., 1992), ou pela diminuição da disponibilidade de aminoácidos na glândula mamária (WU e HUBER, 1994). O uso de fontes de lipídios, tanto de origem animal quanto vegetal, em dietas para ruminantes ainda é motivo de muitas contradições, haja vista o conhecimento ainda restrito dos níveis e das formas de inclusão (protegidas ou não) e de seus efeitos no consumo. (MAIA et. al, 2006).

Quanto às fontes, lipídios ruminalmente inertes (protegidos), como sais de cálcio de ácidos graxos, têm sido uma boa alternativa e seu uso pode se tornar rotineiro em muitos sistemas de produção (NRC, 2001). Porém, em razão do aumento no custo dos insumos e da redução das margens de lucro da atividade leiteira, têm sido estudadas outras fontes lipídicas interessantes do ponto de vista econômico que amenizam o balanço energético negativo da fase 
inicial da lactação e que possuem pouco impacto sobre o metabolismo do rúmen. (NÖRBERG et. al, 2006).

Palmquist \& Jenkins (1980) sugeriram que a inclusão dos lipídios em dietas para ruminantes seja limitada em até $5 \%$ da MS total, visto que os microrganismos ruminais não possuem mecanismos fisiológicos para digeri-los tão eficientemente como o fazem para os carboidratos e as proteínas. Essa ineficiência microbiana para utilização dos lipídios como fonte de crescimento desencadeia uma série de alterações no ambiente ruminal. Um dos principais efeitos deletérios da inclusão de elevadas concentrações de lipídios é a redução na digestão ruminal da fibra (IKWUEGBU \& SUTTON, 1982; WETTSTEIN et al., 2000). A maioria dos trabalhos confirma que o uso de lipídios exerce pouco ou nenhum efeito sobre as atividades da flora microbiana e as demais características do ambiente ruminal, desde que não ultrapasse o valor de $7 \%$ da MS total da dieta (MAIA et. al, 2006).

A redução da concentração de $\mathrm{NH} 3$ ruminal em animais com a inclusão de óleo vegetal na dieta é provocada pelo efeito sobre os protozoários e a redução da população de bactérias desaminadoras (VAN NEVEL \& DEMEYER, 1988). A mudança da população microbiana ruminal com a utilização de lipídios foi constatada também por Lana \& Russell (1996), que notaram que o óleo de milho, assim como os ionóforos monensina e lasalocida, aumentou a resistência das bactérias ruminais à perda do potássio intracelular quando as bactérias foram submetidas in vitro a níveis crescentes de ionóforos. Essa característica é associada à mudança da população microbiana de grampositiva para gram-negativa.

Estudos com inclusão de lipídios na dieta para avaliação do consumo e da digestibilidade dos nutrientes demonstram variações nos resultados, atribuídas à fonte lipídica utilizada, ao nível de inclusão ou à espécie animal (MAIA et al, 2006).

Os lipídios insaturados apresentam efeito tóxico sobre as bactérias celulolíticas do rúmen e reduzem a relação acetato:propionato e, conseqüentemente, o suprimento de ácido acético, precursor direto de $50 \%$ da 
gordura do leite (CHALUPA et al., 1986; PALMQUIST, 1989). A influência dos lipídios sobre os microrganismos ruminais é dependente, ainda, da presença de ácidos graxos livres, da capacidade em formar sais insolúveis, da propriedade de formar barreira física sobre o alimento, dificultando a colonização microbiana, e da quantidade ingerida por dia (SANTOS et. al, 2001).

\section{EFEITO SOBRE O CONSUMO E A DIGESTIBILIDADE}

Em estudo realizado por Maia et al. (2006), avaliando a inclusão de fontes de óleo na dieta de cabras lactantes, observou-se que não houve influência dos tratamentos sobre as ingestões de MS, MO, PB, FDN, CNF e NDT. As fontes de óleos vegetais incluídas na dieta também não influenciaram a excreção fecal (EF), em g/dia, a digestão total (DT), em g/dia, e a digestibilidade total (DIG), em \%, da MS, MO e PB. Em trabalho realizado por Eifert et al, (2005), não foi verificada interação entre óleo e monensina e efeito da monensina sobre estas variáveis. A presença de óleo de soja na dieta reduziu o consumo de matéria seca por dia (CMS), por $100 \mathrm{~kg}$ de PV (CMSP) e por unidade de tamanho metabólico (CMSTM), em média, em 13,8\%, corroborando as indicações do NRC (2001), em que a adição de lipídios pode limitar o consumo por efeitos sobre a fermentação ruminal ou efeitos de ordem metabólica. O consumo de NDT não foi influenciado pelos tratamentos, embora a combinação de óleo de soja e de monensina tenha propiciado redução de $6,97 \%$ no consumo de NDT em relação à dieta com ausência destes ingredientes. A adição de lipídios inibiu o consumo de FDN diário e por $100 \mathrm{~kg}$ de PV (CFDN e CFDNP) em 18,7 e 18,3\%, respectivamente.

Os consumos de MS (CMS), MO (CMO), PB (CPB) e as relações entre CMS, PV e peso metabólico não foram influenciados pela suplementação com lipídios. Diferentemente, os consumos de EE (CEE) e CNF (CCNF) diferiram entre os tratamentos (NÖRBERG et. al, 2006).

Avaliando dietas com diferentes fontes de lipídios para búfalas lactantes Oliveira et al, (2009), constataram que os coeficientes de digestibilidade de 
LIMA JUNIOR, I.F. et al. Uso de fontes lipídicas em dietas de ruminantes de aptidão leiteira. PUBVET, Londrina, V. 6, N. 28, Ed. 215, Art. 1434, 2012.

matéria seca, proteína bruta e carboidratos não-fibrosos foram semelhantes entre as dietas. Um dos efeitos da inclusão de lipídeos em dietas para ruminantes é a diminuição da digestibilidade de nutrientes, principalmente da fibra. As dietas foram elaboradas com teores semelhantes de FDN e pequena variação no extrato etéreo. As dietas sem lipídeo adicional, com grão de soja e com óleo de soja apresentaram coeficientes de digestibilidade de FDN e FDA semelhantes, sugerindo que as condições ruminais mantiveram-se constantes para as três dietas. Neste sentido, Bateman \& Jenkins (1998) mostraram que, se há adequado nível de FDN, o uso de dietas com até 7\% de óleo de soja tem pouco efeito sobre a fermentação ruminal. As menores digestibilidades de FDN e FDA com a dieta com caroço de algodão poderiam ser pelo fato de o grão estar envolto de linter, o que pode dificultar o acesso dos microrganismos e reduzir a digestibilidade.

Segundo Oliveira et al, (2009), a digestibilidade do extrato etéreo da dieta com grão de soja foi menor que a da dieta com óleo de soja, o que pode estar associado ao fato de o óleo de soja proporcionar completa disponibilização lipídica no intestino delgado para formação das micelas e absorção. O mesmo não ocorre com o grão de soja, pois foi administrado inteiro e sua matriz pode ter dificultado o acesso da microbiota ruminal e na formação das micelas do intestino delgado. Silva et al. (2007) também observaram maior coeficiente de digestibilidade do extrato etéreo para dietas com óleo de soja, em comparação ao grão de soja, para cabras em lactação. Ao avaliar o consumo de nutrientes e o coeficiente de digestibilidade em vacas lactantes alimentadas com grão de soja moído no concentrado (0 e 30\%), Pereira et al. (1997) relataram que houve redução no consumo na dieta com $30 \%$ de grão moído e não observaram diferença para a digestibilidade aparente dos nutrientes. Silva et al. (2007) também relataram que a digestibilidade da FDN também foi menor na dieta contendo óleo de soja em comparação com grão de soja para cabras lactantes. Além de a espécie de ruminante utilizada ter sido diferente, o nível de óleo de soja $(4,50 \%)$ e o teor de extrato etéreo $(6,6 \%)$ na dieta foram 
superiores aos utilizados neste trabalho, o que pode explicar as diferenças de resultados.

Verificou-se efeito negativo da adição de fontes de lipídios à dieta não apenas sobre o coeficiente de digestibilidade da parede celular (FDN), mas também sobre a digestão total dos CNF. A digestibilidade da FDN foi maior no tratamento controle (sem óleo), que apresentou média de $36 \%$, enquanto naqueles com suplementação lipídica, o coeficiente de digestibilidade foi, em média, $24 \%$ inferior $(27,62 ; 26,35$ e $27,83 \%$ para os óleos de arroz, de canola e de soja, respectivamente). A inclusão de óleos reduziu aproximadamente $18 \%$ a digestão dos CNF da dieta de cabras Saanen. A digestibilidade da FDN e dos CNF não diferiu entre as dietas suplementadas com óleos de oleaginosas (canola e soja) e de arroz nem entre as fontes oleaginosas (MAIA et al, 2006).

\section{PARÂMETROS FERMENTATIVOS RUMINAIS}

Lipídios insaturados inibiram as bactérias ruminais gram-positivas e estimularam aquelas produtoras de propionato, causando decréscimo na relação acetato:propionato e produção de metano (RICHARDSON et al., 1976; CHALUPA et al., 1984).

O aumento da proporção molar de propionato foi devido ao aumento da produção com concomitante redução da produção de acetato e butirato (VAN NEVEL \& DEMEYER, 1988).

A redução das perdas gasosas tem sido usada para explicar o efeito negativo sobre o consumo de matéria seca pelos inibidores microbianos, como os lipídios e ionóforos (GOODRICH et al., 1984). Entretanto, Vargas et al, (2002), constatou efeito depressor dos lipídios sobre o consumo de matéria seca, sem contudo afetar os parâmetros ruminais, com excessão do butirato e $\mathrm{pH}$. O efeito depressor dos lipídios sobre o consumo de matéria seca deve estar relacionado à inibição do crescimento microbiano e, conseqüentemente, fermentação da fibra, reduzindo, assim, a taxa de passagem da digesta pelo trato gastrintestinal. 
A relação acetato:propionato no líquido ruminal é influenciada pela dieta, variando de 3,5:1 em dieta à base de volumoso a 1,25:1 em dieta rica em concentrado (NAGARAJA et al., 1997). Entretanto, Lana et al. (1998) verificaram maior correlação entre o pH que o nível de concentrado com a relação acetato:propionato. Foi verificada correlação positiva entre o pH e a relação acetato:propionato em experimento realizado por Vargas et al, (2002), confirmando a importância da acidez no estímulo à produção de propionato no rúmen.

Tanto a adição de óleo de soja como a monensina contribuem para aumentar as proporções molares de propionato e reduziram a relação acetato propionato $(A: P)$. A proporção de butirato não foi influenciada pela monensina, mas foi reduzida com a adição de óleo de soja. A proporção de acetato foi reduzida tanto pelo óleo quanto pela monensina, verificando-se efeito de interação entre os tratamentos. $\mathrm{Na}$ interação, a monensina reduziu as concentrações de acetato quando o óleo esteve presente ou ausente na dieta. $\mathrm{Na}$ ausência de monensina, o óleo de soja reduziu a concentração de acetato, mas não alterou a concentração de acetato quando em combinação com monensina (EIFERT et al 2005).

Larson \& Schultz (1970) não encontraram efeito na proporção dos ácidos acético, propiônico e butírico ao compararem dietas contendo ou não óleo de soja para vacas em lactação. Schauff et al. (1992), testando soja integral e/ou sebo bovino em dietas para vacas em lactação, observaram que a proporção molar de acetato e a relação acetato:propionato tenderam a decrescer nas dietas contendo lipídios. $\mathrm{O}$ pH, as proporções molares de butirato, isovalerato e a concentração de amônia não foram alterados pelos tratamentos.

Balieiro Neto \& Melloti (1998), em dietas com 6\% de sebo bovino, verificaram redução dos protozoários totais, redução na proporção molar dos ácidos acético e butírico e aumento do ácido propiônico com a adição de sebo, embora não tenha havido efeito sobre a ingestão de MS e concentração de $\mathrm{N}$ amoniacal. 
Eifert et al, (2005) observou interação significativa entre óleo e monensina sobre a concentração de N-NH3 no rúmen. O óleo de soja reduziu a concentração de nitrogênio amoniacal tanto na ausência (12,30 vs 9,41 $\mathrm{mg} / \mathrm{dL})$ como na presença de monensina na dieta (11,66 vs 10,79 mg/dL). Por outro lado, enquanto a monensina reduziu a concentração de nitrogênio amoniacal nas dietas sem óleo ( 12,30 vs $11,66 \mathrm{mg} / \mathrm{dL})$, o óleo elevou a concentração de 9,41 para 10,79 mg/dL.

Maia et al, (2006), avaliando a inclusão de óleos de arroz, de canola e de soja na dieta constatou que adição das fontes lipídicas não influenciaram a concentração de N-NH3 ruminal, cujo valor médio foi $23,00 \mathrm{mg} / \mathrm{dL}$. Contudo, diferem dos obtidos por Villaça et al. (1999), que, utilizando dietas suplementadas com 5\% de EE na MS, por meio da inclusão de sementes de oleaginosas (soja e algodão) e de óleo de soja na dieta de bezerros holandeses fistulados, verificaram que a concentração média de $\mathrm{N}-\mathrm{NH} 3$ ruminal foi maior com a introdução de óleo de soja em relação às dietas controle e grão de soja, mas não em relação àquela com caroço de algodão. Nestas condições, a concentração média de N-NH3 ruminal encontrada pelos autores foi 7,54 mg/100 mL. Igwuegbu \& Sutton (1982) e Tesfa et al. (1992) demonstraram que óleos insaturados diminuem a concentração de nitrogênio amoniacal, principalmente em razão da diminuição da população de protozoários no ambiente ruminal, entretanto, este efeito não foi avaliado neste estudo. Balieiro Neto \& Melloti (1998) avaliaram dietas com 6\% de sebo bovino e não encontraram efeito negativo sobre a ingestão de MS e a concentração de NNH3 ruminal, mesmo quando houve redução na população de protozoários.

\section{PARÂMETROS SANGUÍNEOS}

O catabolismo da proteína degradável no rúmen é responsável pelo pico da uréia plasmática de 4 a 6 horas após a alimentação de vacas leiteiras, e o metabolismo da proteína não-degradável no rúmen contribui para os níveis plasmáticos de uréia durante o dia (BEQUETTE, 1997). Fergunson et al. (1993) 
LIMA JUNIOR, I.F. et al. Uso de fontes lipídicas em dietas de ruminantes de aptidão leiteira. PUBVET, Londrina, V. 6, N. 28, Ed. 215, Art. 1434, 2012.

reportaram que a taxa de concepção de vacas leiteiras diminui quando o nível de uréia no sangue é superior a $20 \mathrm{mg} / \mathrm{dL}$ no momento da inseminação. Em estudo realizado por Oliveira et al, (2009) com búfalas lactantes, as médias de $\mathrm{N}$-uréico plasmático nos animais mantidos com as dietas com grão de soja $(17,41 \mathrm{mg} / \mathrm{dL})$ e com caroço de algodão $(16,36 \mathrm{mg} / \mathrm{dL})$ mantiveram-se abaixo de $20 \mathrm{mg} / \mathrm{dL}$, enquanto aquelas que receberam as dietas sem lipídeo adicional e com óleo de soja os níveis apresentaram valores superiores (20,5 e 21,6 $\mathrm{mg} / \mathrm{dL}$ para sem lipídeo adicional e óleo de soja, respectivamente).

Silva et al, (2010) Ao comparar fontes de lipídio suplementar na dieta de cabras Saanen em lactação, constatou que a inclusão de semente oleaginosa na dieta das cabras representou um consumo de lipídios da ordem de 85, 78 e 113 (g) para semente de faveleira, torta de faveleira e caroço de algodão, respectivamente e $73 \mathrm{(g}$ ) para o tratamento controle. Essa maior ingestão de lipídios provocou menores consumos de MS $(\mathrm{g} / \mathrm{kg0}, 75)$ e de PB $(\mathrm{g} / \mathrm{kg0}, 75)$ pelos animais que receberam as dietas com sementes oleaginosas. No entanto, os resultados séricos de uréia plasmática não diferiram estatisticamente, diferentemente do que ocorreu com a albumina, onde se observa diferença estatística entre o grupo que recebeu torta de faveleira (TF) e o tratamento controle (TC), o que não ocorreu entre os tratamentos com semente de oleaginosas (SF, TF e CA). Esse resultado sugere que o tratamento com torta de faveleira teve melhor aproveitamento da proteína, uma vez que a albumina é considerada o indicador mais sensível para avaliar o estado nutricional proteico, considerando-se que a sua concentração pode ser alterada pela qualidade da alimentação (GONZÁLEZ, 2000).

Segundo Maia et al, (2006), em estudo com cabras lactantes, a suplementação lipídica da dieta não influenciou o nível de Nitrogênio Uréico no Plasma (NUP), que apresentou valor médio de $18,14(\mathrm{mg} / \mathrm{dL})$, comprovando que, nas condições em que foi realizado o experimento, a utilização das fontes adicionais de óleos na dieta não interferiram neste indicador do metabolismo do nitrogênio. Do mesmo modo, a fonte de óleo empregada na suplementação, sementes de oleaginosas (canola ou soja) ou de cereal, também não interferiu 
neste parâmetro. A concentração de uréia no leite foi superior para o tratamento controle e, a exemplo do que ocorreu com a concentração de uréia plasmática, a análise dos contrastes não mostrou diferença entre as fontes de óleo utilizadas na suplementação. A concentração média deste elemento entre as dietas estudadas foi de $38,88 \mathrm{mg} / \mathrm{dL}$, muito próxima à descrita por Mouro et al. (2002), de 36,87 mg/dL. No entanto, Loor et al. (2002), trabalhando com lipídios adicionados em nível de $5 \%$ da MS da dieta de vacas em lactação, encontraram média de $12,43 \mathrm{mg}$ de $\mathrm{N}$-uréico/dL, que corresponde a aproximadamente $27,62 \mathrm{mg}$ de uréia/dL para este parâmetro.

\section{PRODUÇÃO E COMPOSIÇÃO DO LEITE}

Supondo uma produção de leite $(P L)$ constante, o teor de gordura é o principal fator determinante da quantidade de energia líquida $(E L)$ direcionada à produção de leite pelo animal. Entretanto, atualmente, a remuneração ao produtor por parte das indústrias de laticínios desestimula a produção de leite com teores elevados de gordura (NÖRNBERG et al, 2006). Ao mesmo tempo, pesquisas têm sido realizadas visando reduzir a concentração de gordura no leite e aumentar o teor de ácidos graxos insaturados, especialmente de ácidos graxos linoléico conjugados, os quais têm mostrado benefícios à saúde humana (PARODI, 1999).

Nos animais da raça Jersey utilizados por Nörnberg et al, (2006) (consumo médio de MS de $16 \mathrm{~kg} / \mathrm{dia}$ ), a suplementação com $700 \mathrm{~g}$ de lipídios corresponderia à adição de $4,4 \%$ de $E \mathrm{E}$, o que seria elevado em se tratando de fontes lipídicas não-protegidas. Porém, o nível adicional de 3\% de lipídios em relação ao consumo de MS corresponde à quantidade suplementada $(0,46 \mathrm{~kg})$, a qual, de acordo com a relação anterior, suportaria uma produção extra de $2,3 \mathrm{~kg}$ de leite/dia. No entanto, a diferença verificada para suplementação com óleo de palma protegido foi de 1,32 kg de leite com 3,5\% de gordura/dia. Nas dietas com as outras fontes, as respostas foram menores, de 0,48 e 0,70 kg de leite para Farelo de Arroz Integral + Óleo de Arroz (FAIO) e Farelo de Arroz 
Integral + Sebo Bovino (FAIS), o que seria atendido com 96 e $140 \mathrm{~g}$ de lipídio suplementar, respectivamente. Sendo possível afirmar que a inclusão de gordura protegida na forma de sais de cálcio de ácidos graxos de óleo de palma e farelo de arroz integral, associados a óleo de arroz ou sebo bovino, totalizando $6 \%$ de EE na MS nas dietas (32\% de FDN e 36,5\% de CNF na dieta total), não afetam o consumo voluntário de MS e promovem maior PL. A gordura protegida proporciona também maior PL corrigida para gordura e melhora a eficiência alimentar. Entretanto, independentemente da fonte lipídica estudada, as respostas produtivas foram aquém da eficiência relatada na literatura, indicando a necessidade de mais estudos sobre o assunto.

Santos et al, (2001) avaliaram a inclusão de óleo de soja degomado ou o grão moído de soja para atingir $7 \%$ de lipídios na dieta de vacas em fase inicial de lactação, onde a suplementação com as fontes de lipídio não afetaram a produção e demais características físicoquímicas do leite das vacas. O leite produzido atende a legislação, podendo ser utilizado pelas indústrias de laticínios para comercialização. Da mesma forma Vargas et al, (2002), não observou diferença significativa na produções de leite e leite corrigido para $4 \%$ de pela inclusão de lipídios na dieta dos animais, com valores médios de 20,0 e $18,9 \mathrm{~kg} / \mathrm{dia}$, respectivamente. Os tratamentos também não afetaram a composição do leite, apresentando teores médios de 3,02\% de proteína e $3,64 \%$ de gordura. O uso de lipídios também não afetou outros dados de composição do leite, como lactose, sólidos totais, sólidos desengordurados e densidade, apresentando dados médios de 4,45\%; 12,2\%; 8,56\% e 1,03 kg/L, respectivamente.

A concentração de lactose e de Extrato Seco Desengordurado (ESD) foi reduzida nas dietas contendo óleo. A lactose também diminuiu em relação à fonte de carboidratos utilizada, em que o farelo de trigo apresentou menor conteúdo que a polpa cítrica. Lactose é o mais importante constituinte osmótico do leite, por estar associada à secreção de água e ao volume de leite produzido e por ser dependente de glicose para sua síntese. A glicose pode ser 
originada a partir do propionato do rúmen, do amido absorvido no intestino ou da formação de glicose a partir da gliconeogênese. (EIFERT et al, 2006).

O aumento na produção de leite proporcionado pela suplementação com as fontes lipídicas apresentados por Nörnberg et al, (2006), pode ser explicado pelo acréscimo no aporte metabólico de ácidos graxos pré-formados da dieta. Neste caso, a suplementação possibilitou maior captação de ácidos graxos de cadeia longa pela glândula mamária, disponibilizando maior quantidade de glicose para as células produtoras de leite.

\section{CONCLUSÃo}

As fontes de aditivos lipídicos como as sementes e óleos de oleaginosas e os sais de cálcio de ácidos graxos de cadeia longa consistem em ótimas alternativas à suplementação dietética de animais ruminantes, sobretudo, em se tratando do desafio metabólico da produção de leite. No entanto maiores estudos devem ser realizados para a melhor compreensão das formas de administração das gorduras e sua interação com a microbiota ruminal, afim de aferir com maior precisão seu efeito sobre o comportamento ingestivo e a digestibilidade dos componentes da dieta.

Em relação à interferência das gorduras sobre a produção e a composição do leite os resultados das pesquisas mostram dados controversos, o que enseja novas pesquisas que se dediquem a esse campo de investigação.

\section{REFERÊNCIAS BIBLIOGRAFICAS}

BALIEIRO NETO, G.; MELLOTI, L. Efeitos de diferentes níveis de sebo sobre a fermentação ruminal, contagem de protozoários, proporção de ácidos graxos voláteis e degradabilidade in situ do farelo de soja e do feno de tifton (Cynodon dactylon). In: CONGRESSO NORDESTINO DE PRODUÇÃO ANIMAL, 1., 1998, Fortaleza. Anais... Fortaleza: Ministério da Agricultura, 1998. p.9.

BATEMAN, H.G.; JENKINS, T.C. Influence of soybean oil in high fiber diets fed to nonlactating cows on ruminal unsaturated fatty acids and nutrient digestibility. Journal of Dairy Science, v.81, p.2451-2458, 1998 
BAUMAN, D.E. Regulation of nutrient partitioning during lactation: homeostasis and homeorhesis revisited. In: CRONJÉ, P.B. (Ed.) Ruminant physiology: digestion, metabolism, growth and reproduction. Oxon: CABI Publishing, 2000. p.311-328.

BEQUETTE, B.J.; BACKWELL, F.R.C. Amino acid supply and metabolism by the ruminant mammary gland. Proceedings of Nutrition Society, v.56, p.593-605, 1997.

CHALUPA, W.; RICKABAUGH, B.; HRONFELS, D.S. et al. Rumen fermentation in vitro as influenced by long chain fatty acids. Journal of Dairy Science, v.67, p.1439-1444, 1984.

CHALUPA, W.; VECCHIARELLI, B.; ELSER, A.E. et al. Ruminal fermentation in vivo as influenced by long chain fatty acids. Journal of Dairy Science, v.69, n.5, p.1293-1301, 1986.

EIFERT, E. C da.; LANA, R de. P.; LEÃO, M. I.; ARCURI, P. B. VALADARES FILHO, S de. C.; LEOPOLDINO, W. M.; OLIVEIRA, J da. S.; SAMPAIO, C. B. Efeito da Combinação de Óleo de Soja e Monensina na Dieta sobre o Consumo de Matéria Seca e a Digestão em Vacas Lactantes. R. Bras. Zootec., v.34, n.1, p.297-308, 2005.

EIFERT, E.C.; LANA, R.P.; LANNA, D.P.D. et al. Perfil de ácidos graxos do leite de vacas alimentadas com óleo de soja e monensina no início da lactação. Revista Brasileira de Zootecnia, v.35, n.1, p.231-240, 2006.

FERGUNSON, J.D.; GALLIGAN, D.T.; BLANCHARD, T. et al. Serum urea nitrogen and conception rate: The usefulness of test information. Journal of Dairy Science, v.76, p.37423746, 1993.

GONZÁLEZ, F.H.D. Uso do perfil metabólico para determinar o status nutricional em gado de corte. In: GONZÁLEZ, F.H.D.; BARCELLOS, J.O.; PATIÑO, H.O.; RIBEIRO, L.A. O Perfil metabólico em ruminantes: seu uso em nutrição e doenças nutricionais. Porto Alegre: UFRGS, p.63-74, 2000.

GOODRICH, R.D.; GARRET, J.E.; GUEST, D.R. et al. Influence of monensin on the performance of cattle. Journal of Animal Science, v.58, p.1484-1498, 1984.

IGWUEGBU, O.A.; SUTTON, J.D. The effect of varying the amount of linseed oil supplementation on rumen metabolism in sheep. British Journal of Nutrition, v.48, p.365$375,1982$.

LANA, R.P.; RUSSELL, J.B. Use of potassium depletion to assess adaptation of ruminal bacteria to ionophores. Applied and Environmental Microbiology, v.62, n.12, p.4499-4503, 1996.

LANA, R.P.; RUSSELL, J.B.; Van AMBURGH, M.E. The role of $\mathrm{pH}$ in regulating ruminal methane e ammonia production. Journal of Animal Science, v.76, p.2190-2196, 1998.

LARSON. S.A., SCHULTZ, L.H. Effect of soybeans compared to soybeans oil and meal in the ration of dairy cows, J. Dairy Sci., 53(9):1233-1240, 1970.

LOOR, J.J.; HERBEIN, J.H.; JENKINS, T.C. Nutrient digestion, biohydrogenation, and fatty acid profiles in blood plasma and milk fat from lactating Holstein cows fed canola oil or canolamide. Animal Feed Science and Technology, v.97, p.65-82, 2002. 
MAIA, F. J.; BRANCO, A. F.; MOURO, G. F.; CONEGLINA, S. M.; SANTOS, G. T dos.; MINELLA, T. F.; MACEDO, F. A de. F. Inclusão de fontes de óleo na dieta de cabras em lactação: digestibilidade dos nutrientes e parâmetros ruminais e sangüíneos. R. Bras. Zootec., v.35, n.4, p.1496-1503, 2006.

MOURO, G.F.; BRANCO, A.F.; MACEDO, F.A.F. Substituição do milho pela farinha de mandioca de varredura em dietas de cabras em lactação: fermentação ruminal e concentrações de uréia plasmática e no leite. Revista Brasileira de Zootecnia, v.31, p.1840-1848, 2002.

NAGARAJA, T.G.; NEWBOLD, C.J.; Van NEVEL, C.J. et al. Manipulation of ruminal fermentation. In: HOBSON, P.N.; STEWART, C.S. (Eds.) The rumen microbial ecosystem 2.ed. London: Blackie Academic \& Professional, p.523-632, 1997.

NATIONAL RESEARCH COUNCIL - NRC. Nutrient requirements of dairy cattle. 7.ed. Washington, D.C.: National Academy Press, 2001. 381p.

NÖRNBERG, J. L.; LÓPEZ, J.; STUMPF Jr, W.; COSTA, P. B.; SCHAFHÄUSER Jr, J. Desempenho de vacas Jersey suplementadas com diferentes fontes lipídicas na fase inicial da lactação $\mathbf{R}$. Bras. Zootec., v.35, n.4, p.1431-1438, 2006.

OLIVEIRA, R. L.; BAGALDO, A. D.; LADEIRA, M. M.; BARBOSA, M. A. A de. F.; OLIVEIRA, R. L de.; JAEGER, S. M. P. L. Fontes de lipídeos na dieta de búfalas lactantes: consumo, digestibilidade e N-uréico plasmático. R. Bras. Zootec., v.38, n.3, p.553-559, 2009.

PALMQUIST, D.L.; JENKINS, T.C. Fat in lactation ration: Review. Journal of Dairy Science, v.63, n.1, p.1-14, 1980.

PALMQUIST, D.L. Suplementação de lipídios para vacas em lactação. In: SIMPÓSIO SOBRE NUTRIÇÃO DE RUMINANTES, 6, 1989, Piracicaba. Anais...Piracicaba: FEALQ, p.11-25, 1989.

PEREIRA, C.M.A. et al. Consumo e digestibilidade dos nutrientes para vacas em lactação alimentadas com grão de soja moído no concentrado. In: REUNIÃO ANUAL DA SOCIEDADE BRASILEIRA DE ZOOTECNIA, 34, 1997, Juiz de Fora. Anais ... Viçosa: Sociedade Brasileira de Zootecnia, p.262-264, 1997.

PARODI, P.W. Conjugated linoleic acid and other anticarcinogenic agents of bovine milk fat. Journal of Dairy Science, v.82, n.6, p.1339-1349, 1999.

RICHARDSON, L.F.; RAUN, A.P.; POTTER, E.L. et al. Effect of monensin on ruminal fermentation in vitro. Journal of Animal Science, v.43, p.657-664, 1976.

SANTOS, F. L.; LANA, R. P.; SILVA, M. T. C.; BRANDÃO, S. C. C.; VARGAS, L. H. Produção e Composição do Leite de Vacas Submetidas a Dietas Contendo Diferentes Níveis e Formas de Suplementação de Lipídios. Rev. bras. zootec., 30(4):1376-1380, 2001.

SCHAUFF, D.J. Effects of feeding lactating dairy cows diets containing soybeans and tallow. Journal of Dairy Science, v.75, p.1923-1935, 1992.

SILVA, G de. L. S.; SILVA, A. M de. A.; NÓBREGA, G. H.; AZEVEDO, S. A.; PEREIRA FILHO, J. M.; MENDES, R de. S.; Efeito da inclusão de fontes lipídicas na dieta de cabras em lactação sobre os parâmetros sanguíneos. Ciênc. agrotec., Lavras, v. 34, n. 1, p. 233-239, jan./fev., 2010 
SILVA, M.M.C.; RODRIGUES, M.T.; BRANCO, R.H. et al. Suplementação de lipídios em dietas para cabras em lactação: consumo e eficiência de utilização de nutrientes. Revista Brasileira de Zootecnia, v.36, n.1, p.257-267, 2007.

SNIFFEN, C.J.; O 'CONNOR, J.D.; Van SOEST, P.J et al. A net carbohydrate and protein system for evaluating cattle diets. II Carbohydrate and protein availability. Journal of Animal Science, v.70, p.3562-3577, 1992.

TESFA, A.T.; TOURI, M.R.; SYRJALA-QUIST, L. The effects of increasing levels of rapeseed oil in the diets of lactating milking cows on milk yield, milk compositon, blood an rumen metabolites. World Review Animal Prodution, v.27, p.34-40, 1992.

Van NEVEL, C.J.; DEMEYER, D.I. Manipulation of ruminal fermentation. In: HOBSON, P.N. (Ed.) The rumen microbial ecosystem. Essex: Elsevier, p.387-443, 1988.

VARGAS, L.N.; LANA, R.P.; JHAM, G.N. et al. Adição de lipídeos na ração de vacas leiteiras: parâmetros fermentativos ruminais, produção e composição do leite. Revista Brasileira de Zootecnia, v.31, p.522-529, 2002 (supl. 1).

VILLAÇA, M.; EZEQUIEL, J.M.B.; KRONKA, S.N. Efeito de sementes de oleaginosas inteiras e óleo de soja sobre a digestibilidade in vitro e os padrões ruminais de bezerros Holandeses. Revista Brasileira de Zootecnia, v.28, n.3, p.654-659, 1999.

WETTSTEIN H.R.; MACHMÜLLER A.; KREUZER M. Effect of raw and modified canola lecithins compared to canola oil, canola seed and soy lecithin on ruminal fermentation measured with rumen simulation technique. Animal Feed Science Technology, v.85, p.53-169, 2000.

WU, Z., HUBER, J.T. Relationship between dietary fat supplementation and milk protein concentration in lactating cows: a review. Livest. Prod. Sci., 39(2):141-155, 1994. 
